\title{
Growth and Lead Accumulation Capacity of Lemna minor and Spirodela polyrhiza (Lemnaceae): Interactions with Nutrient Enrichment
}

\author{
Zeliha Leblebici • Ahmet Aksoy
}

Received: 18 November 2009 / Accepted: 23 March 2010/Published online: 13 April 2010

(C) The Author(s) 2010. This article is published with open access at Springerlink.com

\begin{abstract}
A study to understand the biological effects of samples prepared with lead and the effects of lead were conducted on Lemna minor L. and Spirodela polyrhiza (L.) Schleid. This study was intended to test the hypothesis that nutrient enrichment $\left(\mathrm{P}, \mathrm{NO}_{3}{ }^{-}-\mathrm{N}\right.$ and $\mathrm{SO}_{4}{ }^{2-}$ ) enhances the metal tolerance of floating macrophytes. The plants were exposed to $\mathrm{Pb}$ concentrations $0,1,5,10,25$, and $50 \mathrm{mg} \mathrm{l}^{-1}$ for a period of 1,3 , 5 , and 7 days. L. minor accumulated $561 \mathrm{mg} \mathrm{g}^{-1}$ dry weight (dw) $\mathrm{Pb}$, and $S$. polyrhiza accumulated $330 \mathrm{mg} \mathrm{g}^{-1} \mathrm{dw} \mathrm{Pb}$ after 7 days, whereas in the groups enriched with nutrients, L. minor accumulated $128.7 \mathrm{mg} \mathrm{g}^{-1} \mathrm{~Pb}$ and $S$. polyrhiza accumulated $68.7 \mathrm{mg} \mathrm{g}^{-1} \mathrm{dw} \mathrm{Pb}$ after 7 days. Relative growth rates and photosynthetic pigments (chlorophyll a, b, and carotenoid) were measured in L. minor and S. polyrhiza exposed to different $\mathrm{Pb}$ concentrations under laboratory conditions. Relative growth rates were negatively correlated with metal exposure, but nutrient addition was found to suppress this effect. Photosynthetic pigment levels were found negatively correlated with metal exposure, and nutrient addition attenuated chlorophyll decrease in response to metal exposure. Metal and nutrient concentration in water decreased throughout the experiments. The study concluded that nutrient enrichment increases the tolerance of $L$. minor and $S$.
\end{abstract}

Z. Leblebici $(\bowtie) \cdot$ A. Aksoy

Faculty of Science and Arts Department of Biology,

Erciyes University,

38039 Kayseri, Turkey

e-mail: zleblebici@erciyes.edu.tr polyrhiza to metals, that $L$. minor and S. polyrhiza are suitable candidates for the phytoremediation of lowlevel lead pollution, and that L. minor was more effective in extracting lead than was $S$. polyrhiza.

Keywords Nutrient enrichment $\cdot$ Spirodela polyrhiza $\cdot$ Lemna minor $\cdot \operatorname{Lead}(\mathrm{Pb})$.

Photosynthetic pigment

\section{Introduction}

Organisms, populations, biocoenoses, and, ultimately, whole ecosystems are naturally influenced by numerous biotic and abiotic stress factors. With regard to genetic and non-genetic adaptation of organisms and communities to environmental stress, we have to differentiate between the terms tolerance, resistance, and sensitivity. Tolerance is the desired resistance of an organism or community to an unfavorable abiotic (climate, radiation, pollutants) or biotic factors (parasites, pathogens) where adaptive physiological changes (e.g., enzyme induction, immune response) can be observed. Resistance, unlike tolerance, is a genetically derived ability to withstand stress. This means that all tolerant organisms are resistant, but not all resistant organisms are tolerant. However, in ecotoxicology, the dividing line between tolerance and resistance is not always so clear. For example, the phenomenon of pollution-induced community tolerance is described as the phenomenon of community 
shifts toward more tolerant communities when contaminants are present. It can occur as a result of genetic or physiological adaptation within species or populations or through the replacement of sensitive organisms by more resistant organisms. Sensitivity of an organism or a community means its susceptibility to biotic or abiotic change. Sensitivity is low if the tolerance or resistance to an environmental stressor is high, and sensitivity is high if the tolerance or resistance is low (Markert et al. 2003).

Environmental exposure to toxic trace metals is one of the critical issues in environmental and public health. Unfortunately, traditional chemical and physical remediation techniques in vogue are limited by the pattern of discharge. Hence, phytoremediation, a plant-based green technology, is proposed as a viable alternative. Its relative inexpensiveness and ecofriendliness have made it an attractive method for water and soil remediation (Prasad et al. 2010; Rahman et al. 2008). It is well known that aquatic plants accumulate metals absorbed from the environment and concentrate them into trophic chains with cumulative effect (Outridge and Noller 1991; Tremp and Kohler 1995). Significant lead accumulation has been observed in other aquatic plants like Nerium oleander (Aksoy and Öztürk 1997), Lemna minor L. (Mohan and Hosetti 1997; Gamczarska and Ratajczak 2000), Ipomoea aquatica (Göthberg et al. 2004), and Ceratophyllum demersum (Mishra et al. 2006).

The use of aquatic macrophytes, such as water hyacinth, duckweed, and water lettuce in wastewater treatment, has attracted global attention in recent years (Reed et al. 1995; Gijzen and Khonker, 1997; Van der Steen et al. 1999; Vermaat and Hanif 1998) as these plants can be grown on the surface of stabilization ponds and could contribute to nutrient recovery from wastewater. Duckweed is a floating aquatic macrophyte belonging to the botanical family Lemnaceae and can be found worldwide on the surface of nutrientrich fresh and brackish waters (Zimmo 2003).

Lee and Wang (2001) reported that an increase in nitrate concentration resulted in a significant increase in cadmium accumulation in Ulva fastica. According to Hadad et al. (2007), nutrient enrichment either attenuated (chromium and zinc) or suppressed (nickel) root biomass decrease in response to metal exposure in Salvinia herzogii. Appenroth et al. (2008) reported that sulfates reduce chromate toxicity in duckweeds. Although studies have been conducted on heavy metal accumulation in Spirodela polyrhiza and L. minor (Rahman et al. 2008; Appenroth et al. 2003; Appenroth et al. 2001), the effect of nutrient addition on these species metal tolerance is not known.

The aim of this paper was to investigate whether nutrient enrichment enhance the metal tolerance of floating macrophytes and whether such nutrient enrichment enable the growth of floating vegetation in constructed wetlands at metal concentrations that would otherwise inhibit plant viability.

\section{Materials and Methods}

\subsection{Plant Material and Treatment Conditions}

Plants of species L. minor and S. polyrhiza were obtained from Soysalli-Kayseri $\left(38^{\circ} 23^{\prime} 500^{\prime \prime \prime} \mathrm{N}, 035^{\circ}\right.$ 21'919" E, 1,075 m), Turkey. The chemical composition of the pond water was (mean $\pm \mathrm{SD}$ ): $\mathrm{pH} 6.4 \pm 0.1$; conductivity $=92 \pm 8 \mu \mathrm{S} \mathrm{cm}{ }^{-1} ; \mathrm{NH}_{4}{ }^{+}-\mathrm{N}=0.021 \pm$ $0.01 \mathrm{mg} \mathrm{l}^{-1} ; \mathrm{NO}_{3}{ }^{-}-\mathrm{N}=0.02 \pm 0.001 \mathrm{mg} \mathrm{l}^{-1}, \mathrm{NO}_{2}{ }^{-} \mathrm{N}=$ $0.002 \pm 0.001 \mathrm{mg} \mathrm{l}^{-1} \mathrm{SO}_{4}{ }^{2-}=0.2 \pm 0.03 \mathrm{mg} \mathrm{l}^{-1}$. Before metal treatment, plants were acclimatized for 5 days under laboratory conditions $\left(23^{\circ} \mathrm{C}\right.$ and $14-\mathrm{h}$ photoperiod, $\left.350 \mu \mathrm{mol} \mathrm{m} \mathrm{s}^{-1}\right)$. In this study, lead chloride $\left(\mathrm{PbCl}_{2}\right)$ was used without further purification for experimental treatments. Plants were treated with different concentrations of $\mathrm{Pb}\left(0,5,10,25\right.$, and $\left.50 \mathrm{mg} \mathrm{l}^{-1}\right)$ and maintained in double deionized water in 500-ml conical flasks under the aforementioned conditions for periods of 1, 3, 5, and 7 days. Plant growth rates in response to metal exposures were compared with exposures enriched with $5 \mathrm{mg} \mathrm{l}^{-1} \mathrm{P}\left(\mathrm{KH}_{2} \mathrm{PO}_{4}\right), 5 \mathrm{mg} \mathrm{l}^{-1} \mathrm{NO}_{3}{ }^{-}$ $\mathrm{N}\left(\mathrm{KNO}_{3}\right)$, and $\mathrm{SO}_{4}{ }^{2-}\left(\mathrm{K}_{2} \mathrm{SO}_{4}\right.$; Hadad et al. 2007). Flasks without metals grown alongside each set of experimental groups served as controls. After harvesting, plants were washed with double deionized water. Plants were placed on blotting paper and allowed to drain for $5 \mathrm{~min}$ before weighing. Water samples were filtered through for nutrient determinations. Nitrate, phosphate, and sulfate were determined by Hach Lange DR 2800 spectroscopy. All treatments were carried out in triplicate.

L. minor and S. polyrhiza relative growth rates were calculated in each group according to Hunt's equation:

$$
R=\ln W_{2}-\ln W_{1 /} T_{2}-T_{1}
$$


where $R$ is the relative growth rate $\left(\mathrm{g}^{-1}\right.$ day $\left.{ }^{-1}\right), W_{1}$ and $W_{2}$ are the initial and final fresh weights, respectively, and $\left(T_{2}-T_{1}\right)$ is the experimental period (Hunt 1978).

\subsection{Lead Quantification}

Harvested plants were washed thoroughly with double deionized water, blotted, and oven-dried at $80^{\circ} \mathrm{C}$. Each sample was then digested with $10 \mathrm{ml}$ pure $\mathrm{HNO}_{3}$ using a CEM-MARS 5 (CEM Corporation Matthews, NC, USA) microwave digestion system (maximum power, 1,200 W; power, 100\%; ramp, 20:00 min; pressure, $180 \mathrm{psi}$; temperature, $210^{\circ} \mathrm{C}$; and hold time, 10:00 $\mathrm{min}$ ). After digestion, the volume of each sample was adjusted to $25 \mathrm{ml}$ using double deionized water. Determinations of $\mathrm{Pb}$ concentrations in plant and water samples were carried out by inductively coupled plasma optical emission spectroscopy (Varian-Liberty II, ICP-OES; Duman et al. 2009). Peach leaves (NIST, SRM-1547) were used

\section{a}

L. minor
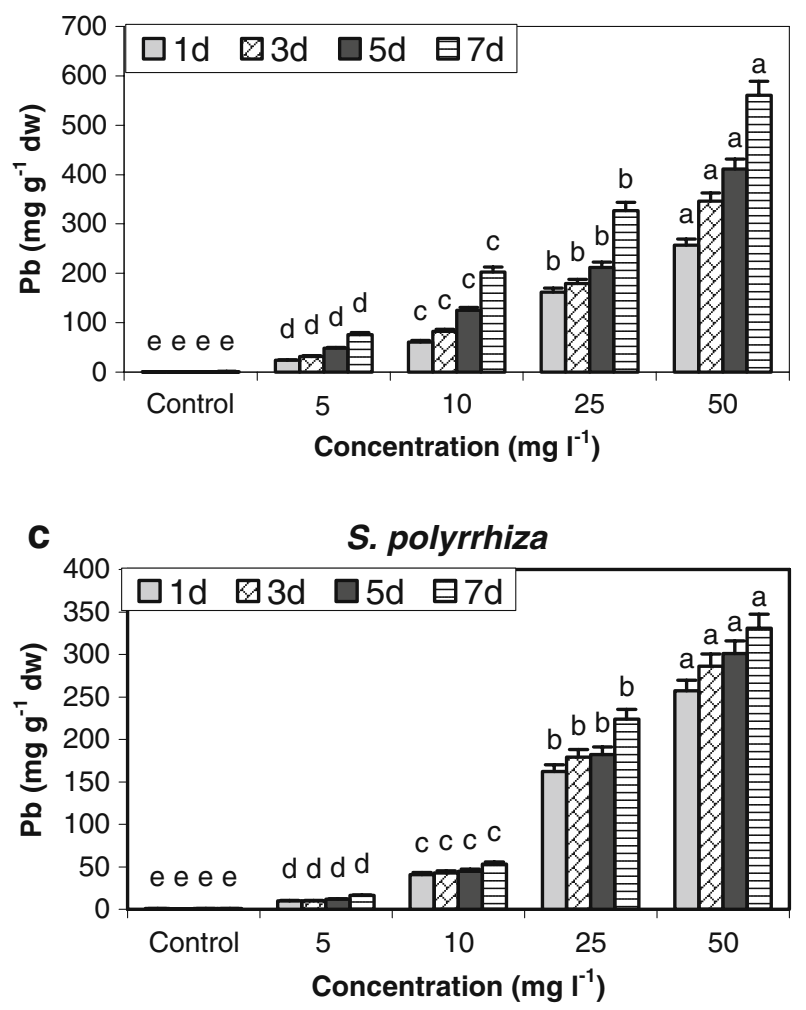

Fig. 1 Accumulation of $\mathrm{Pb}(\mathbf{a}), \mathrm{Pb}+$ nutrients by L. minor (b), and $\mathrm{Pb}$ and $(\mathrm{d}) \mathrm{Pb}+$ nutrients by $S$. polyrhiza (c) exposed to different concentrations over various periods of time. All values as reference material; also, all analytical procedures were performed for reference material. Recoveries of lead from NIST, SRM-1547 $\left(0.81 \pm 0.01 \mu \mathrm{g} \mathrm{l}^{-1}\right)$ and certified value of lead of NIST, SRM $1547(0.89 \pm$ $0.02 \mu \mathrm{g} \mathrm{l}^{-1}$ ) analyses were determined by ICP-OES. $\mathrm{Pb}$ concentrations were below the detection limits of the method $\left(\mathrm{Pb}<0.2 \mu \mathrm{g}^{-1}\right)$.

The bioconcentration factor (BCF) was calculated as follows (Rahmani and Stenberg 1999):

$\mathrm{BCF}=\mathrm{Pb}$ in plant biomass $\left(\mathrm{mg} \mathrm{kg}^{-1}\right) / \mathrm{Pb}$ in solution $\left(\mathrm{mg}^{-1}\right)$

\subsection{Plant Growth Parameters}

Plant biomass was measured on the basis of fresh weight. Photosynthetic pigments of treated and untreated plants $(100 \mathrm{mg})$ were extracted in $80 \%$ chilled acetone in the dark. After centrifugation at $10,000 \times \mathrm{g}$ for $10 \mathrm{~min}$, absorbance of the supernatant

b

L. minor
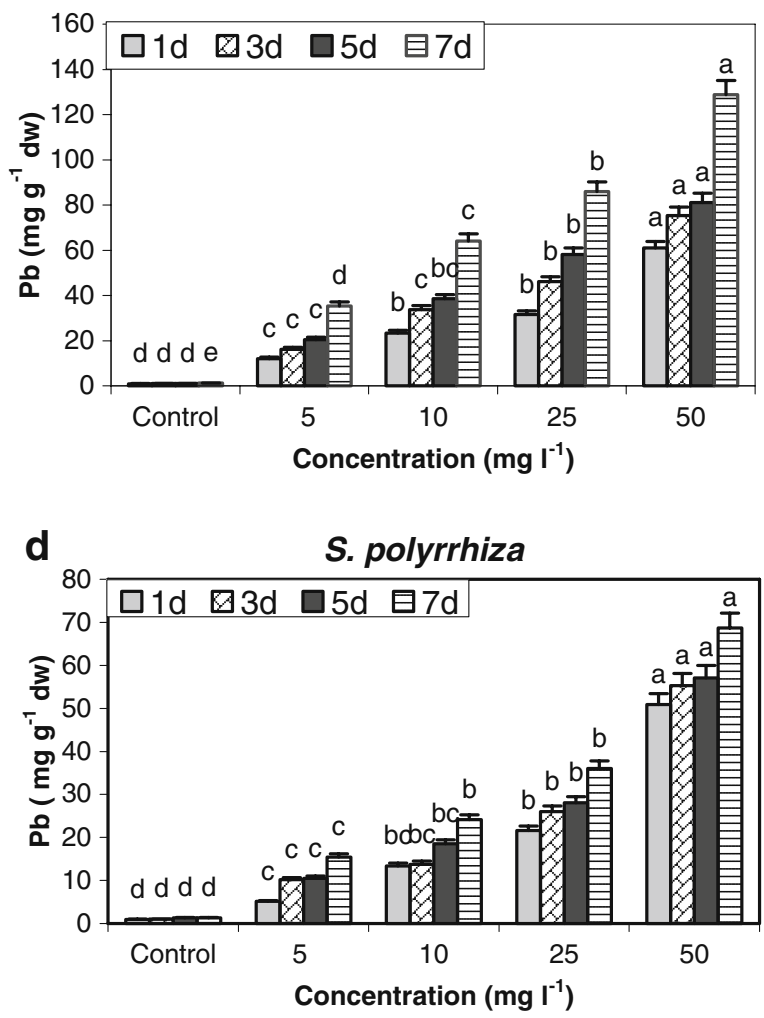

are means of triplicates \pm SD. ANOVA significance was set at $p \leq 0.01$. Different letters indicate significantly different values at a particular time point (DMRT, $p \leq 0.05$ ) 
was taken at 450,645, and $663 \mathrm{~nm}$. The content of chlorophylls and carotenoids were estimated as previously described (Witham et al. 1971).

\subsection{Statistical Analysis}

Two-way analysis (ANOVA) was done with all the data to confirm the variability of data and validity of results, and Duncan's multiple range test (DMRT) was performed to determine the significant difference between treatments. Statistical Package for the Social Sciences statistical program was used for statistical analysis (Kinnear and Gray 1994).

\section{Results and Discussion}

3.1 Accumulation of Lead and its Effect on Growth of Plants

$\mathrm{Pb}$ bioaccumulation was measured in Lemna fronds. The highest $\mathrm{Pb}$ accumulation was seen at a dose of $50 \mathrm{mg}^{-1}$. The percent of the total $\mathrm{Pb}$ accumulated (561 $\mathrm{mg} \mathrm{g}^{-1}$ ) on day 7 at $50 \mathrm{mg} \mathrm{l}^{-1}$ was $13.5 \%$ on day $1,36.1 \%$ on day 3 , and $58.2 \%$ on day 5 (Fig. 1a). In the groups enriched with nutrients, $\mathrm{Pb}$ accumulation at $50 \mathrm{mg} \mathrm{l}^{-1}$ was $27.5 \%$ on day $1,49.8 \%$ on day 3 , and $66.8 \%$ on day 5 of the total $\mathrm{Pb}$ accumulated (128.7 $\mathrm{mg} \mathrm{g}^{-1}$ ) on day 7 (Fig. 1b). Bioaccumulation of $\mathrm{Pb}$ was measured in Spirodela fronds. The plants were found to accumulate high amounts of $\mathrm{Pb}$ in a concentration- and time-dependent manner. The highest $\mathrm{Pb}$ accumulation was observed at a dose of $50 \mathrm{mg} \mathrm{l}^{-1}$. The total percentage of $\mathrm{Pb}$ accumulated $\left(330 \mathrm{mg} \mathrm{g}^{-1}\right)$ on day 7 at $10 \mathrm{mg} \mathrm{l}^{-1}$ was $4.9 \%$ on day $1,16 \%$ on day 3 , and $67.8 \%$ on day 5 (Fig. 1c). In the groups enriched with nutrients, $\mathrm{Pb}$ accumulation at $50 \mathrm{mg} \mathrm{l}^{-1}$ was $22.4 \%$ on day $1,35 \%$ on day 3 , and $52.4 \%$ on day 5 of the total $\mathrm{Pb}$ accumulated (68.7 $\mathrm{mg} \mathrm{g}^{-1}$ ) on day 7 (Fig. 1d). Metal concentrations in plants increased with metal concentration as well as over time. In the present study, high accumulation of $\mathrm{Pb}$ was observed in $L$. minor and $S$. polyrhiza over a 7-day period, and L. minor was more effective in accumulating $\mathrm{Pb}$ than $S$. polyrhiza. Over a period, nutrient enrichment reduced the accumulation of $\mathrm{Pb}$ in growing plants.

Relative growth rates of $L$. minor decreased in the presence of $\mathrm{Pb}$ in a concentration-dependent manner
(Fig. 2a). However, the treatments enriched with nutrients did not show a similar correlation $(R=$ 0.980). Relative growth rates of $S$. polyrhiza declined with $\mathrm{Pb}$ in a concentration-dependent manner (Fig. 2b), but the treatments enriched with nutrients did not show similar correlation $(R=0.950)$. Therefore, nutrient addition prevented the decline in relative growth rates in response to metal exposure (Fig. 2a, b).

Growth rates of L. minor and S. polyrhiza declined with increasing $\mathrm{Pb}$ concentrations. However, nutrient enrichment led to increased growth rates at $\mathrm{Pb}$ concentrations that impaired growth in the nonenriched groups.
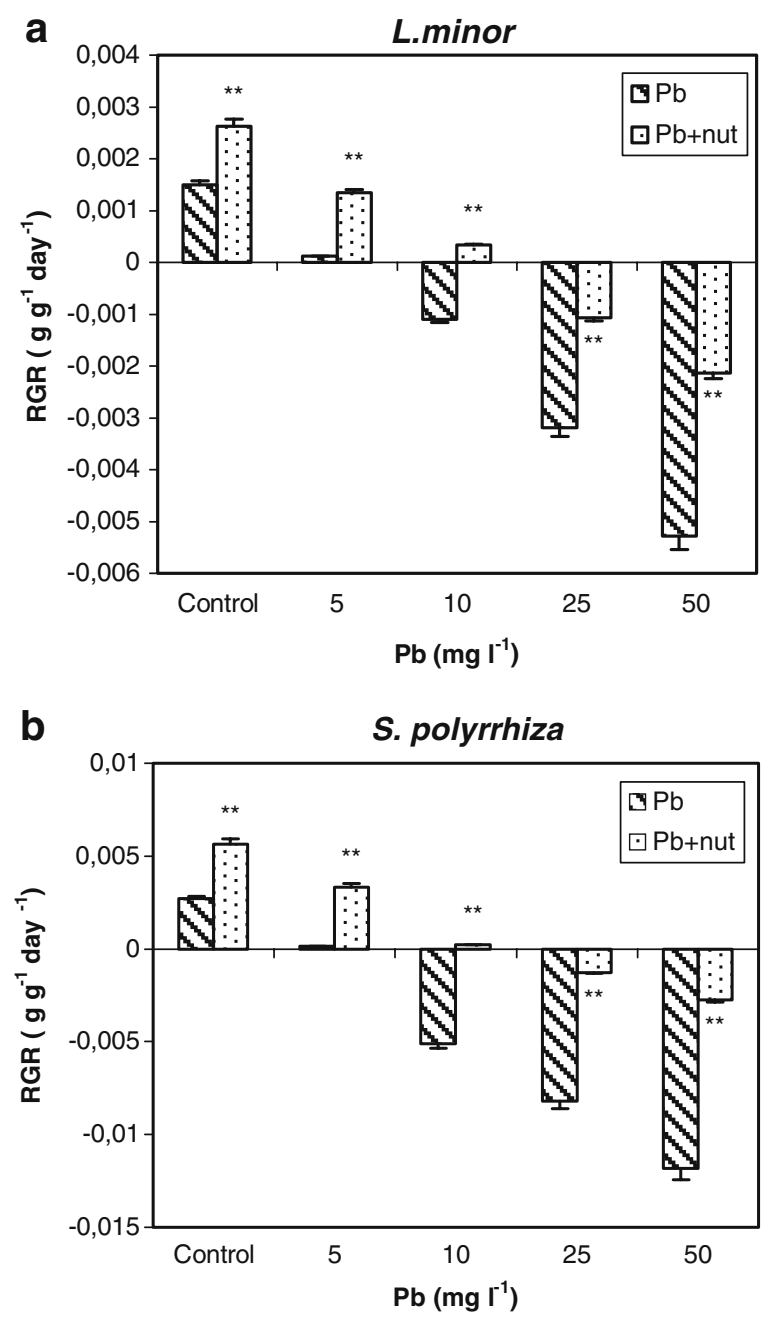

Fig. 2 Relative growth rates of $\mathrm{Pb}$ treated with L. minor (a) and $S$. polyrhiza (b). The bars represent standard deviation. ${ }^{* *} p<0.01$ indicates a significant difference between the two treatments 
Appenroth et al. (2008) investigated the modification of chromate toxicity by sulfate in duckweeds. The authors explained that sulfate influences the toxicity of chromate mainly by chromate uptake, with negligible impact on other physiological processes. Rahman et al. (2008) reported on the uptake of arsenate in $S$. polyrhiza and its interactions with $\mathrm{PO}_{4}{ }^{3-}$ and $\mathrm{Fe}$ ions. Their study found that arsenate uptake in S. polyrhiza occurred through the phosphate uptake pathway and by physicochemical adsorption on Fe plaques of plant

a

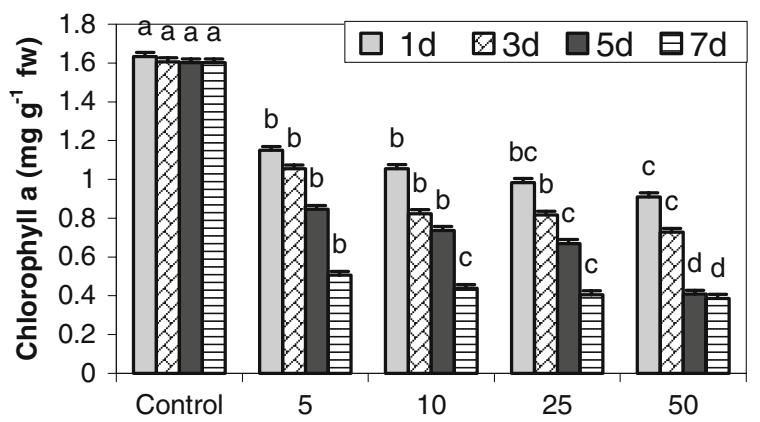

C
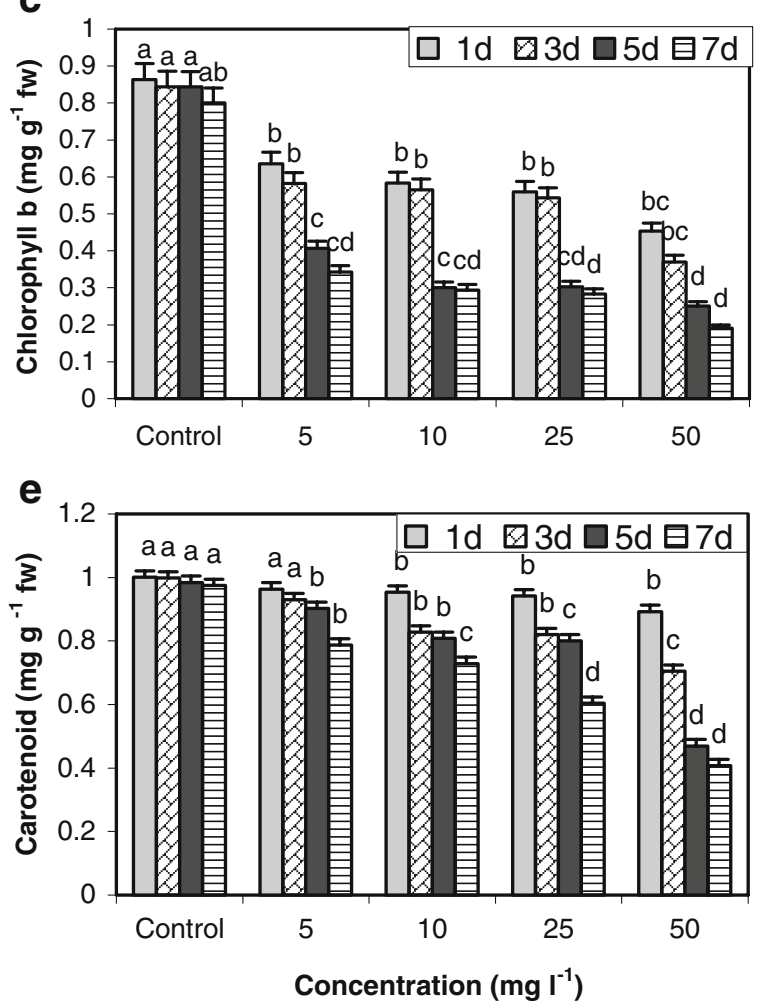

Fig. 3 Effect of different concentrations of $\mathrm{Pb}$ and nutrients on chlorophyll $a(\mathbf{a}, \mathbf{b})$, chlorophyll $b$ (c, d), and carotenoid $(\mathbf{e}, \mathbf{f})$ contents of $L$. minor. All values are means of triplicates \pm SD. surfaces as well. In line with our results, Hadad et al. (2007) found that nutrient enrichment enabled growth of Salvinia hergozii at $\mathrm{Zn}$ and $\mathrm{Ni}$ exposures that impaired growth in plants without nutrient addition. Göthberg et al. (2004) found high metal concentrations in I. aquatica cultivated for human consumption in freshwater courses near Bangkok that were receiving variable amounts of cultural nutrient loads. The authors proposed fertilization as a means to attenuate metal accumulation. Their experimental work agreed with

b
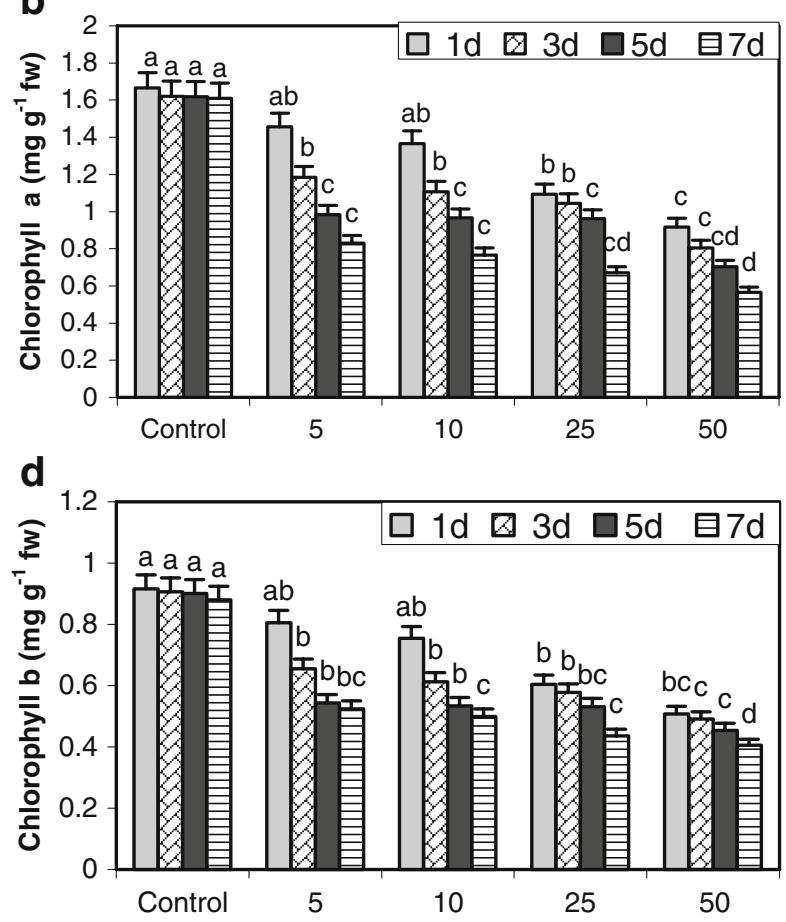

f

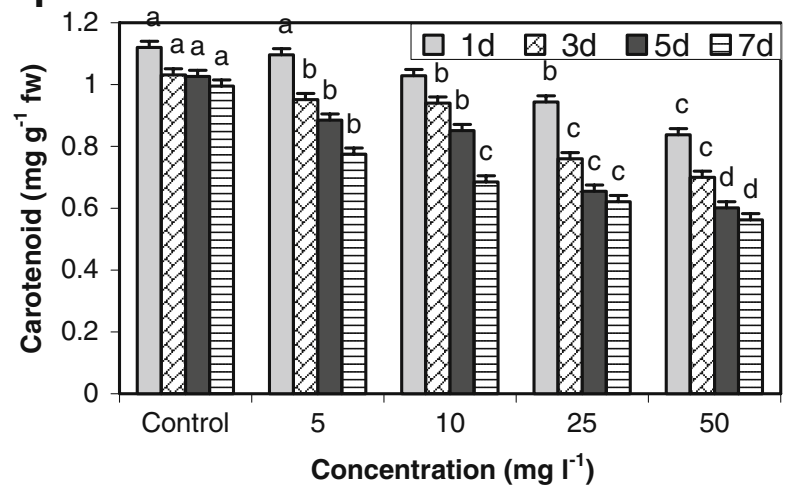

ANOVA significance was set at $p \leq 0.01$. Different letters indicate significantly different values at a particular time point (DMRT, $p \leq 0.05$ ) 
our findings and showed that nutrient enrichment led to increased I. aquatica tolerance to cadmium, lead, and mercury. Decrease in lead and mercury accumulation was observed with increasing concentrations of nutrients, as was observed for lead in the present study.

\subsection{Effect of Metals on Photosynthetic Pigments}

Chlorophyll concentration in L. minor was negatively correlated with $\mathrm{Pb}$ exposures (Fig. 3). Nutrient enrichment attenuated the observed decrease in

a
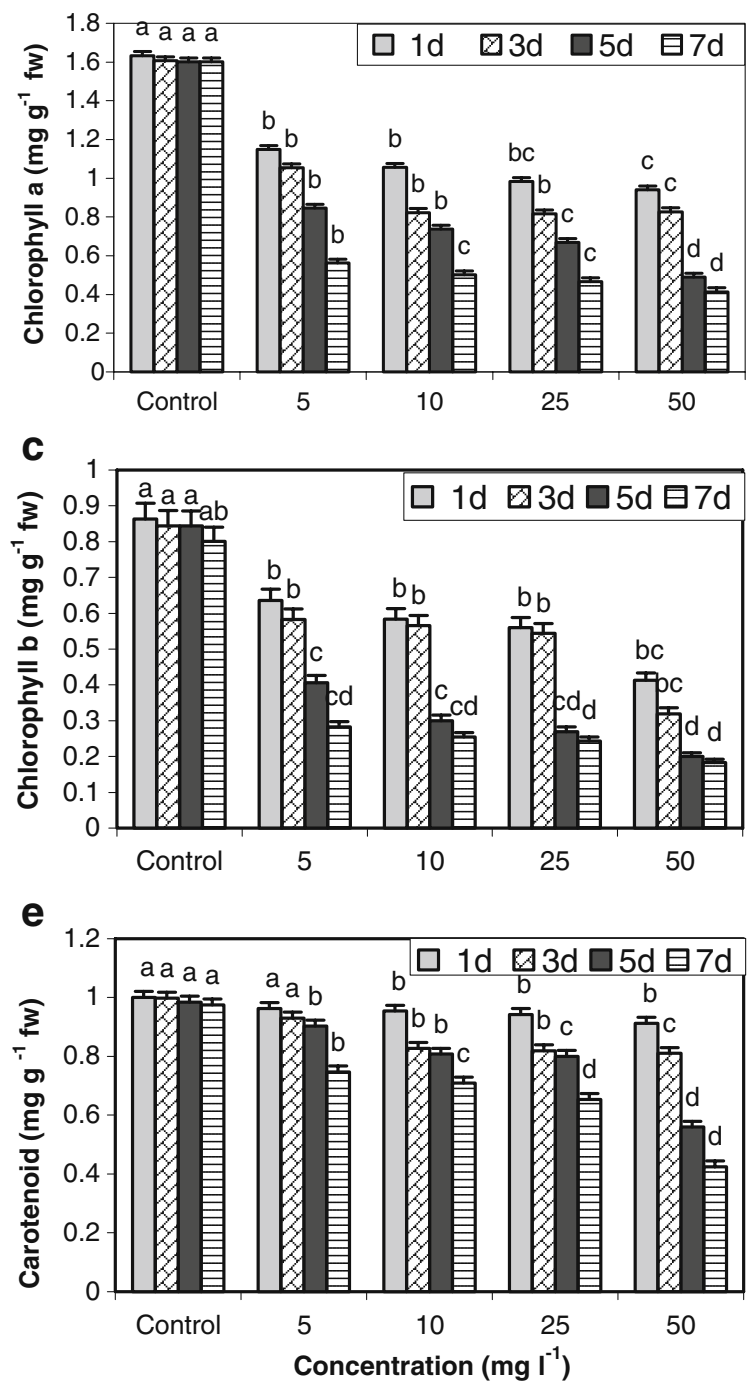

Fig. 4 Effect of different concentrations of $\mathrm{Pb}$ and nutrients on chlorophyll $a$ (a, b), chlorophyll $b$ (c, d), and carotenoid (e, f) contents of $S$. polyrhiza. All the values are means of triplicates \pm chlorophyll concentration by $\mathrm{Pb}$ exposures. Levels of chl $a$ decreased in a $\mathrm{Pb}$ concentration-dependent and time-dependent manner, with a minimum value of $0.386 \mathrm{mg} \mathrm{g}^{-1}$ in the $50-\mathrm{mg} \mathrm{l}^{-1} \mathrm{~Pb}$ group (Fig. 3a). In the nutrient-enriched, 50-mg $1^{-1} \mathrm{~Pb}$ group, chl $a$ levels were reduced to a minimum value of $0.565 \mathrm{mg} \mathrm{g}^{-1}$ fresh weight on day 7 (Fig. 3b). The value of chl $b$ content was $0.190 \mathrm{mg} \mathrm{g}^{-1}$ at the highest concentration of $\mathrm{Pb}$ by day 7 (Fig. 3c), while in the nutrient-enriched groups, chl $b$ reached a minimum value of $0.405 \mathrm{mg} \mathrm{g}^{-1}$ fresh weight on
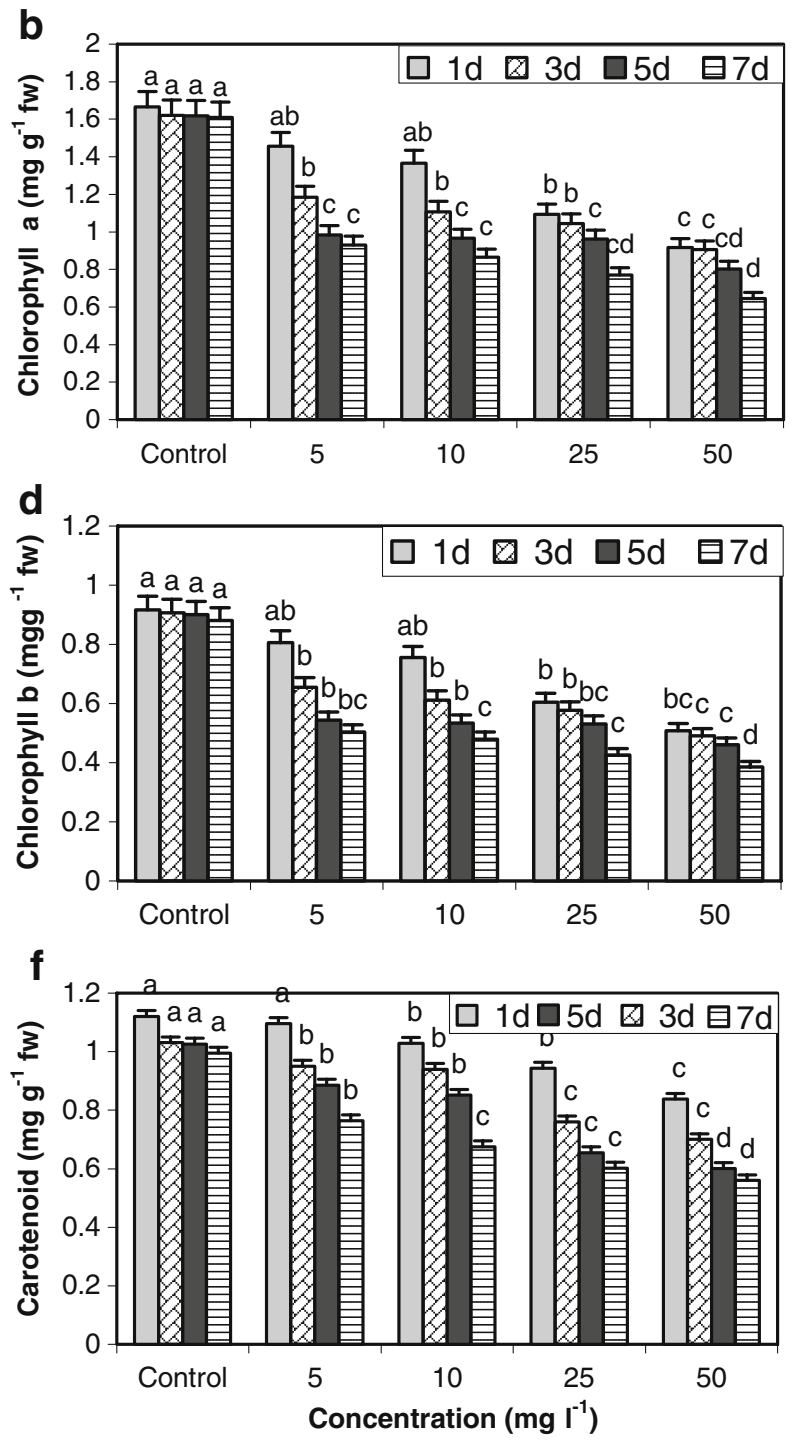

SD. ANOVA significance was set at $p \leq 0.01$. Different letters indicate significantly different values at a particular time point (DMRT, $p \leq 0.05$ ) 
Fig. 5 Effect of $\mathrm{Pb}$ concentration in solution on the metal accumulation in the $\mathrm{Pb}(\mathbf{a}), \mathrm{Pb}+$ nutrients in $L$. minor (b), and $\mathrm{Pb}$ bioconcentration factor. Plants were exposed to $\mathrm{Pb}$ for 7 days. Vertical bars denote $\mathrm{SD}, n=3$

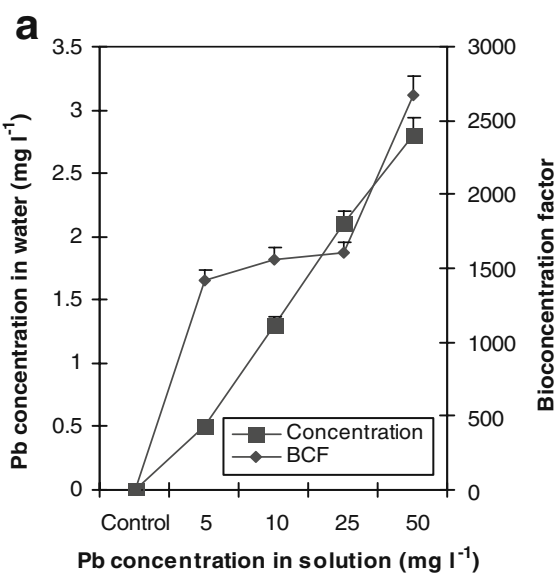

day 7 with $50 \mathrm{mg} \mathrm{l}^{-1} \mathrm{~Pb}$ (Fig. 3d). Carotenoid content decreased at all $\mathrm{Pb}$ concentrations, with the minimum value difference being $0.407 \mathrm{mg} \mathrm{g}^{-1}$ in the $50 \mathrm{mg}^{-1}$ group on day 7 (Fig. 3e). In $50 \mathrm{mg} \mathrm{l}^{-1} \mathrm{~Pb}$ treated groups with nutrient enrichment, however, carotenoid levels on day 7 were $0.561 \mathrm{mg} \mathrm{g}^{-1}$ (Fig. 3f).

Chlorophyll concentration in $S$. polyrhiza was negatively correlated with $\mathrm{Pb}$ exposures (Figs. 3 and 4). Nutrient enrichment attenuated the observed reduction in chlorophyll concentration caused by $\mathrm{Pb}$ exposures. When Spirodela fronds were exposed to $\mathrm{Pb}$ concentrations of $5 \mathrm{mg}^{-1}$ or higher, a dosedependent decrease of chlorophyll pigments was also observed, with a minimum chl $a$ value of $0.414 \mathrm{mg} \mathrm{g}^{-1}$ fresh weight on day 7 at $50 \mathrm{mg} \mathrm{l}^{-1}$ compared to $1.601 \mathrm{mg} \mathrm{g}^{-1}$ in controls (Fig. 4a). On day 7, the 50-mg $\mathrm{l}^{-1} \mathrm{~Pb}$-treated groups with nutrient enrichment of chl $a$ reached a minimum value of $0.645 \mathrm{mg} \mathrm{g}^{-1}$ fresh weight (Fig. 4b). For $\mathrm{Pb}$ concentrations exceeding $5 \mathrm{mg} \mathrm{l}^{-1}$, the decrease in content of chl $b$ was gradual and more inhibited than that of chl $a$. At $50 \mathrm{mg} \mathrm{l}^{-1} \mathrm{~Pb}$ concentration, the amount of chl $b$ reached a minimum value of $0.183 \mathrm{mg} \mathrm{g}^{-1}$ fresh weight on day 7 (Fig. 4c), whereas in the nutrient-enriched groups, chl $b$ reached a minimum value of $0.385 \mathrm{mg} \mathrm{g}^{-1}$ fresh weight on day 7 (Fig. 4d). As with chlorophylls, carotenoid levels also declined gradually at concentrations up to $5 \mathrm{mg}^{-1} \mathrm{~Pb}$ until day 3, and by day 7 , carotenoid content was significantly lower than controls at all concentrations; the minimum value of $0.424 \mathrm{mg} \mathrm{g}^{-1}$ was attained in the $50-\mathrm{mg} \mathrm{l}^{-1} \mathrm{~Pb}$ group (Fig. 4e). In nutrient-enriched groups exposed to $50 \mathrm{mg} \mathrm{l}^{-1} \mathrm{~Pb}$, the

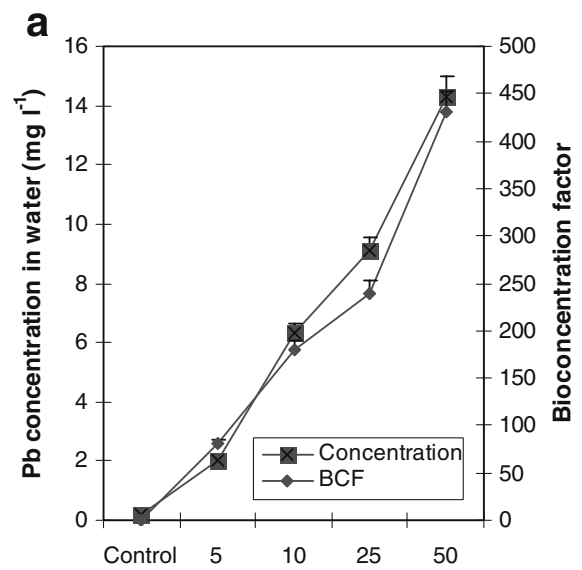

$\mathrm{Pb}$ concentration in solution $\left(\mathrm{mg} \mathrm{l}^{-1}\right)$

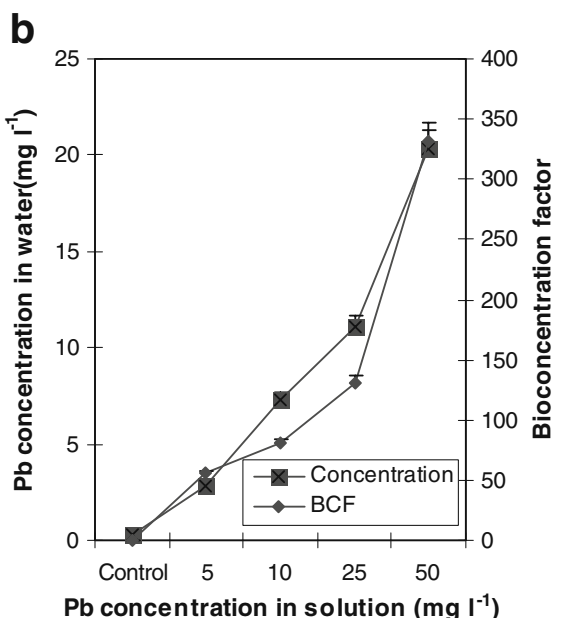

Fig. 6 Effect of $\mathrm{Pb}$ concentration in solution on the metal accumulation in the $\mathrm{Pb}(\mathbf{a}), \mathrm{Pb}+$ nutrients in $S$. polyrhiza (b), and $\mathrm{Pb}$ bioconcentration factor. Plants were exposed to $\mathrm{Pb}$ for 7 days. Vertical bars denote $\mathrm{SD}, n=3$ 
minimum value of carotenoid was $0.559 \mathrm{mg} \mathrm{g}^{-1}$ fresh weight on day 7 (Fig. 4f).

Chlorophyll concentrations in $L$. minor and $S$. polyrhiza were negatively correlated with $\mathrm{Pb}$ accumulation, but nutrient enrichment mitigated the decrease in chlorophylls. In fronds treated with $\mathrm{Pb}, \mathrm{a}$ concentration of $5 \mathrm{mg} \mathrm{l}^{-1}$ was sufficient to cause a decrease in pigment molecules, indicating that although lead is a non-essential metal ion, it was toxic for the growth and development of plants and, at high levels, could be a strong inhibitor of photosynthesis (Frankart et al. 2002; Vavilin et al. 1995). The loss in chlorophyll content could be due to peroxidation of chloroplast membranes or replacement of magnesium in chlorophyll molecules by $\mathrm{Pb}$ ions (Mal et al. 2002; Sandmann and Boger 1980).
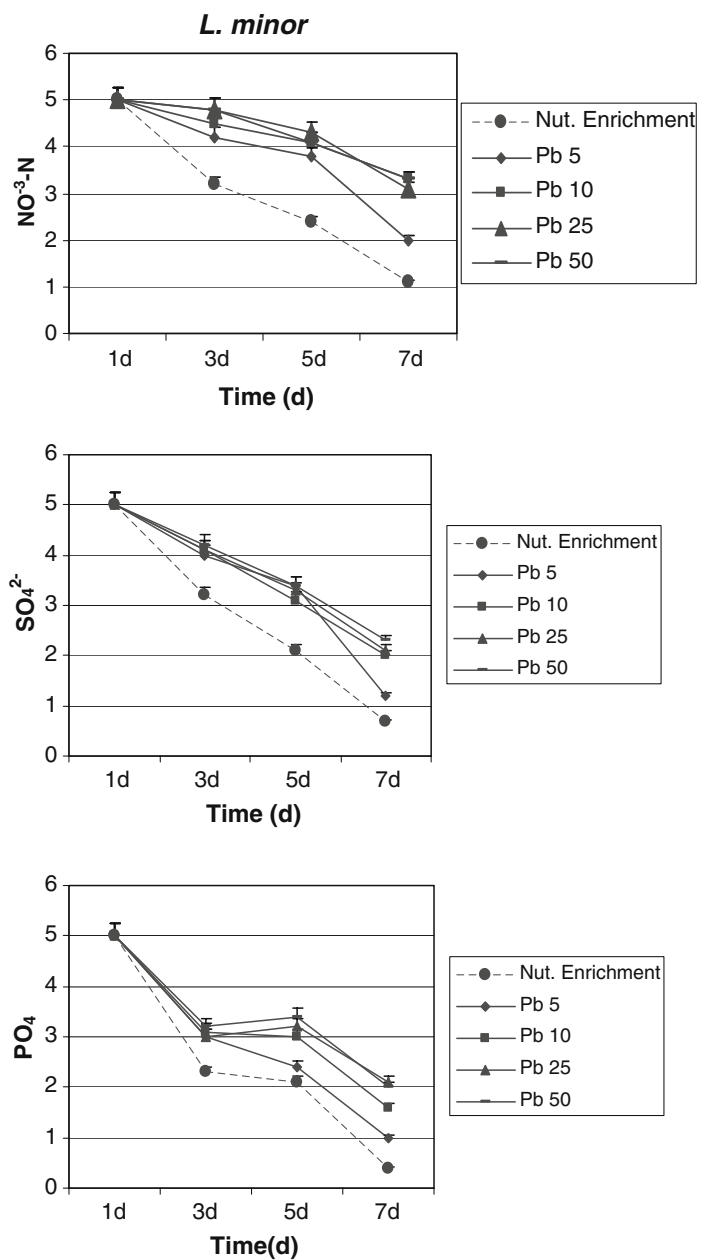

\subsection{Metal and Nutrient Concentrations in Water}

A rapid decrease in $\mathrm{Pb}$ concentration in water was observed without differences between the metal and nutrient-enriched treatments in L. minor (Fig. 5a, b). $\mathrm{Pb}$ concentrations in water decreased with time, reaching a plateau after about 5 days of exposure in L. minor. $\mathrm{Pb}$ concentrations in water were significantly lower in the treatments enriched with nutrients than in the treatments without enrichment in $S$. polyrhiza (Fig. 6a, b). Metal concentrations in water decreased with time in all the experiments. According to Zayed et al. (1998), a plant which is considered a good accumulator must have a BCF over 1,000. Our results confirmed that L. minor and S. polyrhiza were good accumulators of $\mathrm{Pb}$ (Figs. 5 and 6) and have potential
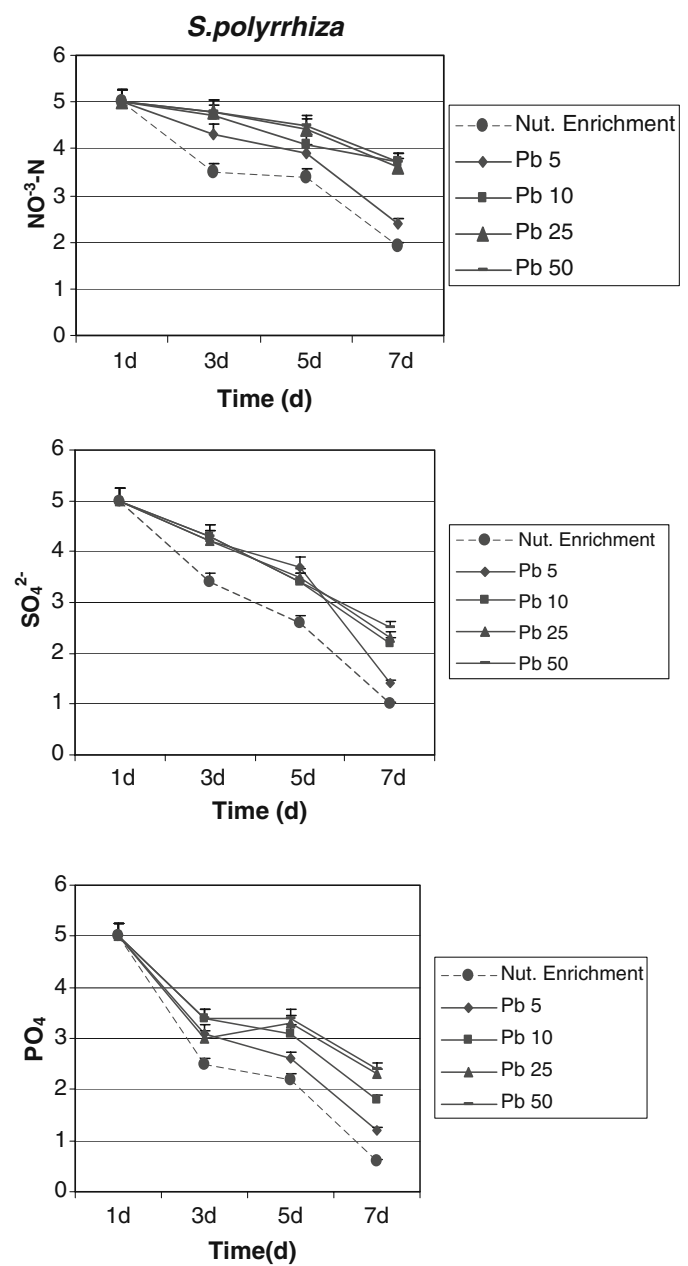

Fig. 7 Nitrate $\left(\mathrm{NO}_{3}{ }^{-}-\mathrm{N}\right)$, sulfate $\left(\mathrm{SO}_{4}{ }^{2-}\right)$, and phosphate $\left(\mathrm{PO}_{4}\right)$ water concentrations obtained under nutrient enrichment in the $\mathrm{Pb}$ by L. minor and $S$. polyrhiza for a long time. Bars represent standard deviation 
for the remediation of $\mathrm{Pb}$-polluted water. Our study also indicated that $S$. polyrhiza was less effective than L. minor. According to Khellaf and Zerdaoui (2009), L. gibba was less effective than L. polyrrhiza used by Sharma and Gaur (1994). However, the species was more effective than L. minor and S. polyrhiza reported in the work of Jain et al. (1989) and Mishra and Tripathi (2008), respectively.

Nitrate, phosphate, and sulfate concentrations in water decreased with time in the nutrient-enriched treatments in L. minor and S. polyrhiza (Fig. 7). $\mathrm{Pb}$ exposure reduced nutrient removal from water. Lower nitrate concentrations were attained in the conical flasks with nutrient enrichment than in the $\mathrm{Pb}$ exposures (Fig. 7). In line with our results, Hadad et al. (2007) found that zinc exposure reduced nutrient removal from water. Göthberg et al. (2004) emphasized the role of competition between metals and nutrients for active stress in the uptake by roots and in the plant translocation system.

\section{Conclusions}

Contaminated water with toxic and undesirable heavy metals is a serious environmental problem which may be solved with phytoaccumulation. In this study, we investigated the toxic effects of $\mathrm{Pb}$ on $L$. minor and $S$. polyrhiza and bioaccumulation of this metal. L. minor was more effective than S. polyrhiza. Our results showed that nutrient enrichment raised the tolerance of L. minor and S. polyrhiza to metal contamination. This effect has important implications in the use of constructed wetlands for industrial wastewater treatment. Many processes in the metallurgical industry produce wastewater containing high concentrations of metal ions. Higher tolerance would be useful for wastewater treatment as it allows macrophyte growth at metal concentrations that would otherwise impair their development. Nutrient addition will thus aid metal removal by increasing macrophyte production, leading to higher metal uptake by the macrophyte biomass and thereby enhancing overall biological activity to reach higher metal retention levels in the detritus fractions.

Acknowledgments We thank Erciyes University for help with this study. This work was supported by the Research Fund of the Erciyes University. Project number is FBT-08-528.
Open Access This article is distributed under the terms of the Creative Commons Attribution Noncommercial License which permits any noncommercial use, distribution, and reproduction in any medium, provided the original author(s) and source are credited.

\section{References}

Aksoy, A., \& Öztürk, M. (1997). Nerium oleander L. as a biomonitor of lead and other heavy metal pollution in Mediterranean environments. Science of the Total Environment, 205, 145-150.

Appenroth, K. J., Stöckel, J., Srivastava, A., \& Strasser, R. J. (2001). Multiple effects of chromate on the photosynthetic apparatus of Spirodela polyrhiza as probed by OJIP chlorophyll a fluorescence measurements. Environmental Pollution, 115, 49-64.

Appenroth, K. J., Keresztes, A., Sarvari, E., Jaglarz, A., \& Fischer, W. (2003). Multiple effects of chromate on Spirodela polyrhiza: Electron microscopy and microscopy and biochemical investigations. Plant Biology, 5, 315323.

Appenroth, K. J., Luther, A., Jetschke, G., \& Gabrys, H. (2008). Modification of chromate toxicity by sulphate in duckweeds (Lemnaceae). Aquatic toxicology, 89, 167-171.

Duman, F., Leblebici, Z., \& Aksoy, A. (2009). Growth and bioaccumulation characteristics of watercress (Nasturtium officinale R. BR.) exposed to cadmium, cobalt and chromium. Chemical speciation and bioavailability, 21, 257-265.

Frankart, C., Eullaffroy, P., \& Vernet, G. (2002). Photosynthetic responses of Lemna minor exposed to xenobiotics, copper and their combinations. Ecotoxicology and Environmental Safety, 53, 439-445.

Gamczarska, M., \& Ratajczak, L. (2000). Metabolic reponses of Lemna minor to lead ions. I. Growth, chlorophyll level and activity of fermentative enzymes. Acta Physiology Plant, 22, 423-427.

Gijzen, H., \& Khonker, M. (1997). An overview of the ecology, physiology, cultivation, and application of duckweed, literature review. Report of Duckweed Research Project, Dhaka, Bangladesh.

Göthberg, A., Greger, M., Holm, K., \& Bengtsson, B. E. (2004). Influence of nutrient levels on uptake and effects of mercury, cadmium and lead in water spinach. Journal of environmental quality, 33, 1247-1255.

Hadad, H. R., Maine, M. A., Natale, G. S., \& Bonetto, C. (2007). The effect of nutrient addition on metal tolerance in Salvinia herzogii. Ecological Engineering, 31, 122131.

Hunt, R. (1978). Plant growth analysis. Studies in biology (p. 67). London: Edward Arnold.

Jain, S. K., Vasudevan, P., \& Jha, N. K. (1989). Removal of some heavy metals from polluted water by aquatic plants: Studies on duckweed and water velvet. Biological Wastes, 28, 115-126.

Khellaf, N., \& Zerdaoui, M. (2009). Phytoaccumulation of zinc by the aquatic plant, Lemna gibba L. Bioresource technology, 100, 6137-6140. 
Kinnear, P. R., \& Gray, C. D. (1994). SPSS for Windows made simple (pp. 97-120). USA: Erlbaum.

Lee, W. Y., \& Wang, W. X. (2001). Metal accumulation in the green macroalgae Ulva fasciata: Effects of nitrate, ammonium and phosphate. Science of the Total Environment, 278, 11-22.

Mal, T. K., Adorjan, A. L., \& Corbertt, A. L. (2002). Effect of copper on growth of an aquatic macrophytes Elodea canadensis. Environmental Pollution, 120, 307-311.

Markert, B. A., Breure, A. M., \& Zechmeister, H. G. (2003). Bioindicators and biomonitors: Principles, concepts and application (pp. 17-18). Amsterdam: Elsevier Science.

Mishra, K. V., \& Tripathi, B. D. (2008). Concurrent removal and accumulation of heavy metals by the three aquatic macrophytes. Bioresource technology, 99, 7091-7097.

Mishra, S., Srivastava, S., Tripathi, R. D., Kumar, R., Seth, C. S., \& Gupta, D. K. (2006). Lead detoxification by Coontail (Ceratophyllum demersum L.) involves induction of phytochelatins and antioxidant system in response to its accumulation. Chemosphere, 65, 1027-1039.

Mohan, B. S., \& Hosetti, B. B. (1997). Potential phytotoxicity of lead and cadmium to Lemna minor grown in sewage stabilization ponds. Environmental Pollution, 98, 233-238.

Outridge, P., \& Noller, B. (1991). Accumulation of toxic trace elements by freshwater vascular plants. Rev Environ Cont Toxicol, 121, 2-63.

Prasad, M. N. V., Freitas, H., Fraenzle, S., Wuenschmann, S., \& Markert, B. (2010). Knowledge explosoion in phytotechnologies for environmnetal solutions. Environmental Pollution, 158, 18-23.

Rahman, A. M., Hasegawa, H., Ueda, K., Maki, T., \& Rahman, M. M. (2008). Arsenic uptake by aquatic macrophyte Spirodela polyrhiza L.: Interactions with phosphate and iron. Journal of hazardous materials, 160, 356-361.

Rahmani, G. N. H., \& Stenberg, S. P. K. (1999). Bioremoval of lead from water using Lemna minor. Bioresource technology, 70, 225-230.
Reed, S. C., Crites, R. W., \& Miilebrooks, E. J. (1995). Natural systems for waste management and treatment (2nd ed.). New York: McGraw-Hill.

Sandmann, G., \& Boger, P. (1980). Copper-mediated lipid peroxidation processes in photosynthetic membranes. Plant Physiology, 66, 797-800.

Sharma, S. S., \& Gaur, J. P. (1994). Potential of Lemna polyrrhiza of removal of heavy metals. Ecological Engineering, 4, 37-43.

Tremp, H., \& Kohler, A. (1995). The usefulness of macrophytemonitoring systems, exemplified on eutrophication and acidification of running waters. Acta Botanica Gallica, 142, 541-550.

Van der Steen, P., Brenner, A., Van Buuren, J., \& Oron, G. (1999). Post-treatment of UASB reactor effluent in integrated duckweed and stabilization pond system. Water Research, 33, 615-620.

Vavilin, D. V., Polynov, V. A., Matorin, D. N., \& Venediktov, P. S. (1995). Sublethal concentration of copper stimulates photosystem II photoinhibition in Chlorella pyrenoidosa. Journal of plant physiology, 146, 609-614.

Vermaat, J. E., \& Hanif, K. M. (1998). Performance of common duckweed species (Lemnaceae) and the waterfern Azolla filiculoides on different types of waste water. Water Research, 32, 2569-2576.

Witham, F. H., Blaydes, D. F., \& Deulin, R. M. (1971). Experiments in plant physiology (p. 245). New York: Van Nostrand Reinhold.

Zayed, A., Gowthaman, S., \& Terry, N. (1998). Phyoaccumulation of traces elements by wetland plants: I. Duckweed. Journal of environmental quality, 27, 715-721.

Zimmo, O. (2003). Nitrogen transformations and removal mechanisms in algal and duckweed waste stabilization ponds. PhD thesis, International Institute for Infrastructural, Hydraulic and Environmental Engineering, Delft, The Netherlands. 